\title{
As histórias em quadrinhos nos processos de leitura e escrita de jovens e adultos da Educação do Campo: uma proposta de letramento estético
}

The comic books in the reading and writing processes of youth and adults in rural education: a proposal of aesthetic literacy

Gustavo Cunha de Araújo ${ }^{1}$

José Carlos Miguel ${ }^{2}$

\section{Resumo}

Esta pesquisa teve por objetivo investigar como se desenvolve o letramento estético a partir de signos visuais e da escrita para compreender a realidade do jovem e do adulto brasileiros da Educação do Campo. Partindo de ampla pesquisa bibliográfica e de análise documental acerca da Educação de Jovens e Adultos (EJA) e da Educação do Campo adotamos como procedimento metodológico o Experimento Didático-Formativo, em diálogo com a teoria Histórico-Cultural. Os sujeitos participantes são estudantes jovens e adultos de uma licenciatura em Educação do Campo de uma universidade brasileira. Os resultados indicam avanços nos processos de leitura e de escrita após a produção de histórias em quadrinhos pelos estudantes, em especial, no que se refere à autoria. Portanto, se conseguem melhorar a escrita e a leitura a partir dessa linguagem, entendemos que isso é belo, pois tem caráter de obra bem feita e coerente, uma vez que melhoraram os seus processos de leitura e escrita. Nesta perspectiva, a

${ }^{1}$ Doutor em Educação pela UNESP. Mestre em Educação pela UFMT. Graduado em Artes Visuais pela UFU. Professor da Universidade Federal do Tocantins na graduação e no Programa de Pós-Graduação em Educação.

${ }^{2}$ Doutor em Educação. Professor vinculado ao Departamento de Didática e ao Programa de Pós-Graduação em Educação da Universidade Estadual Paulista Júlio de Mesquita Filho, campus de Marília, São Paulo, Brasil.

Interfaces da Educ., Paranaíba, v.11, n.32, p. 632 - 661, 2020

ISSN 2177-7691

Recebido em 09 de janeiro 2020 e aceito em 21 de agosto de 2020 
estética se refere não apenas a uma obra bem feita, mas a um objeto ou pensamento que tem mais que um valor artístico, isto é, que ofereça uma harmonia e equilíbrio em suas formas, uma qualidade estética.

Palavras-chave: Educação do Campo. História em Quadrinhos. Jovens e Adultos.

\section{Abstract}

This research aimed to investigate how aesthetic literacy develops from visual signs and writing to understand the reality of Brazilian youth and adult education in the Rural Education. Based on a broad bibliographic research and documentary analysis about Youth and Adult Education (EJA) and Rural Education we adopted as a methodological procedure the Didactic-Formative Experiment, in dialogue with the Historical-Cultural theory. Participants are young and adult students of a degree in Rural Education from a Brazilian university. Results indicate advances in reading and writing processes after the production of comic books by the students, especially with regard to authorship. Therefore, one can improve writing and reading from this language; we understand that this is beautiful, as it has a well done and coherent work character, since they have improved their reading and writing processes. In this perspective, aesthetics refers not only to a well done work, but to an object or thought that has more than an artistic value, that is, that offers harmony and balance in its forms, an aesthetic quality.

Keywords: Rural Education. Comics Books. Youth and Adults.

\section{Introdução}

Esta pesquisa é parte de um projeto de investigação mais amplo desenvolvido com os jovens e os adultos do curso de Licenciatura em Educação do Campo com habilitação em Artes e Música, de uma 
universidade pública brasileira. Teve como objetivo investigar como se desenvolve o letramento estético a partir de signos visuais e da escrita para compreender a realidade do jovem e do adulto da Educação do Campo. Fundamentado na teoria Histórico-Cultural, adotou como método o Experimento Didático-Formativo desenvolvido nas aulas da disciplina de História em Quadrinhos (HQ) desse curso.

A concepção de jovens e adultos que assumimos nesta pesquisa é aquela que se refere a sujeitos que buscam aprender e se desenvolver ao longo da vida ${ }^{1}$ por meio da interação social e apropriação da cultura, independente da idade; que trazem consigo experiências de vida e que não são apenas os da Educação Básica, mas também jovens e adultos que cursam o ensino superior, como é o caso desta investigação; querem ir à universidade porque eles querem aprender e atuar para construir uma nova realidade, quiçá empregos melhores com um diploma de ensino superior. Em diferentes momentos de suas vidas, buscam fazer usos da leitura e da escrita no dia a dia para que possam assinar um documento, ler e compreender a bula de um remédio, entre tantos outros motivos que os trazem para a universidade.

Contudo, no retorno à instituição escolar, não encontram, por vezes, infraestrutura adequada e materiais didáticos apropriados para o ensino, o que, somado a conteúdos e metodologias inadequadas, acabam prejudicando diretamente o desenvolvimento da leitura e da escrita, dificultando a

\footnotetext{
${ }^{1}$ Até meados de 1997 o movimento voltado à consolidação da educação como direito público subjetivo no Brasil se alinhava com o paradigma internacional de "Educação para Todos", destacado na Conferência Mundial de Educação realizada em Jomtien, Tailândia, 1990, com participação de delegação brasileira. No entanto, é o Plano Decenal de Educação de 1994 que fixa metas para ensino de jovens e adultos pouco ou não escolarizados. A mudança de paradigma, concebendo o direito à educação e aprendizagem para todos os cidadãos (crianças, jovens, adultos e idosos) ao longo da vida, com vistas ao desenvolvimento socialmente justo, sustentável e solidário, é posição defendida a partir da V CONFINTEA (V Conferência Internacional de Educação de Adultos, realizada em Hamburgo, Alemanha, de 14 a 18 de julho de 1997, resultando na elaboração do documento denominado "Educação de Adultos: Declaração de Hamburgo, a Agenda para o Futuro") e que possibilitou ampliar a concepção de EJA na educação brasileira (UNESCO, 1998). Assim, os anseios pela construção de uma sociedade justa, igualitária e voltada para o desenvolvimento humano impõe a consolidação do paradigma da "Educação Para Todos ao Longo da Vida". É essa concepção que assumimos nesta pesquisa, uma vez que nos referimos a jovens e adultos universitários, oriundos do campo, e não da Educação Básica.
}

Interfaces da Educ., Paranaíba, v. 11, n.32, p. 632 - 661, 2020 
inserção social e excluindo de práticas letradas essenciais para consciência da realidade e participação efetiva no meio sociocultural no qual estão inseridos.

As pessoas constroem conhecimento por diferentes meios e um deles é pela arte, pois, além de ser uma área do saber, portanto, conhecimento humano, proporciona aprendizagem criativa, possibilitando amplo desenvolvimento das ações mentais pela atividade de estudo, fundamental para o desenvolvimento do pensamento. Por ser uma produção essencialmente humana, de contribuir para a produção de significados no processo educativo, em diferentes momentos da vida, a arte é importante para a educação e necessária para a vida, portanto.

A atividade de estudo a qual nos referimos se baseia na formação de conceitos que ocorre na aprendizagem (DAVÍDOV, 1988). Refere-se aos conceitos espontâneos (presentes antes do sujeito ir à escola) e aos conceitos científicos (que já existem e se juntam aos conceitos espontâneos, ao longo de sua escolarização). Contudo, é preciso que o professor planeje e organize um ensino (desenvolvimental) que possibilite executar diferentes tarefas e ações, para que possa desenvolver conceitos, avançar na aprendizagem e amadurecer as suas funções psicológicas superiores. Foi seguindo os pressupostos dessa teoria que desenvolvemos a pesquisa.

Nesse sentido, buscamos revelar nesta pesquisa que é possivel, a partir das histórias em quadrinhos, desenvolver o que entendemos por letramento estético, por meio de signos visuais e da escrita para compreender a realidade do jovem e do adulto da Educação do Campo por meio de uma atividade de estudo que possibilite a eles desenvolver as suas funções psíquicas superiores; portanto, avançar na aprendizagem e na tomada de consciência, pelo envolvimento com a arte. Esse papel formativo e desenvolvimental tem na teoria Histórico-Cultural o principal diálogo para as reflexões, argumentações e análises construídas nesta pesquisa. 


\section{Procedimentos metodológicos face aos pressupostos teóricos}

Partindo de pesquisa bibliográfica e análise documental, realizamos entrevistas $^{2}$ semiestruturadas com 39 estudantes jovens e adultos camponeses de uma universidade pública brasileira, do curso de Educação do Campo com Habilitação em Artes e Música, os quais assinaram o Termo de Consentimento Livre e Esclarecido - TCLE, aceitando participar voluntariamente desta pesquisa ${ }^{3}$. As narrativas produzidas foram gravadas em áudio e vídeo e, posteriormente, transcritas por nós. Nosso objetivo foi gerar informações relevantes para a pesquisa, que pudessem nos auxiliar a responder questões levantadas nesta investigação, principalmente no que se refere à Educação do Campo. Elaboramos blocos de perguntas que foram respondidas oralmente pelos sujeitos, de forma individual, ao longo de quase oito meses; portanto, não foi realizado um Grupo Focal ou respostas coletivas, mas perguntas que foram respondidas individualmente pelos estudantes que aceitaram participar da pesquisa, com vistas a obtermos de cada educando as suas percepções e vivências a respeito dos temas abordados nas entrevistas: Educação do Campo, Artes, Leitura e Escrita. Ao elaborar as perguntas, estava claro para nós que as semiestruturadas fossem as mais adequadas, pois, no decorrer das entrevistas surgiriam outras questões importantes para as análises das informações obtidas na pesquisa de campo.

$\mathrm{Na}$ elaboração das perguntas levamos em consideração os objetivos e o problema desta investigação. E, considerando a extensão do artigo, focaremos as análises apenas em parte das histórias em quadrinhos produzidas, sendo escolhidas para este artigo duas histórias significativas, num universo de 39 histórias ${ }^{4}$, e alguns trechos das entrevistas realizadas

\footnotetext{
${ }^{2}$ As entrevistas tinham 61 perguntas sobre artes, Educação do Campo, leitura e escrita.

3 Entregamos no campus universitário pesquisado uma Declaração de Autorização para a realização desta pesquisa, que foi assinada pela diretora do campus e pelo coordenador do curso de Educação do Campo, autorizando a realização desta investigação nesse campus universitário.

4 Cada aluno participante desta pesquisa elaborou individualmente uma história em quadrinhos, totalizando 39 histórias produzidas.
}

Interfaces da Educ., Paranaíba, v.11, n.32, p. 632 - 661, 2020 
com os alunos, relativas à Educação do Campo, uma vez que se referem à realidade na qual se inserem, vivem, trabalham e se constituem enquanto sujeitos históricos. Isso não limitou as análises dos dados, uma vez que essas análises dialogam empiricamente e teoricamente com as demais histórias produzidas por eles na pesquisa desenvolvida. Assim, vivenciamos situações, ocorrências e ações desenvolvidas nas aulas experimentais de História em Quadrinhos, procurando selecionar e reduzir os dados coletados para que pudessem ser descritos, categorizados, analisados e interpretados nesta pesquisa.

No que concerne às análises dos dados, os estudos de Vigotski (2010, 2009, 2007, 2001, 2000, 1999, 1998), bem como de seus colaboradores, baseados no materialismo histórico e dialético, fundamentaram as análises que realizamos. O elemento principal para a elaboração do método por Vigotski está relacionado aos estudos naturalísticos e dialéticos de Marx e Engels, voltados para o entendimento da história do indivíduo. Vigotski (2010) considera que o homem não apenas faz parte de seu meio, mas é agente criador desse meio, mantendo relações sociais com o mundo a sua volta. Adotar na pesquisa teses do Materialismo Histórico Dialético na forma de análise e interpretação dos dados, na perspectiva da teoria HistóricoCultural, significou entender não apenas a história no processo de mudança desse indivíduo, enquanto sujeito histórico e as contradições presentes na realidade, mas compreender também o desenvolvimento de seus processos mentais a partir de uma atividade de estudo.

O curso de Educação do Campo da universidade pesquisada é ofertado na modalidade presencial em dois campi. Foi implantado em 2013 por meio do Edital n. ${ }^{\circ}$ 02/2012- SESU5/SETEC6/SECADI7/MEC 8 -2012 com apoio do $\mathrm{PROCAMPO}^{9}$, com as suas primeiras turmas iniciando no primeiro semestre de 2014. O ingresso no curso ocorre mediante vestibular, sendo que as

\footnotetext{
${ }^{5}$ Secretaria de Educação Superior.

${ }^{6}$ Secretaria de Educação Profissional e Tecnológica.

${ }^{7}$ Secretaria de Educação Continuada, Alfabetização, Diversidade e Inclusão.

8 Ministério da Educação.

9 Programa de Apoio à Formação Superior em Licenciatura em Educação do Campo. Interfaces da Educ., Paranaíba, v. 11, n.32, p. 632 - 661, 2020
} 
vagas são distribuídas pelo sistema universal, através de cota para indígenas, quilombolas e egressos do ensino médio de escolas públicas. As entradas no vestibular ocorrem anualmente, sendo que a primeira entrada no curso ocorreu em 2014 com 120 alunos. Atualmente, a entrada no curso é de 40 alunos por ano10:

Quadro 1 - Quantitativos de alunos da universidade pesquisada.

\begin{tabular}{|l|c|c|c|c|c|}
\hline $\begin{array}{l}\text { Cursos de Licenciatura } \\
\text { em Educação do Campo }\end{array}$ & $\mathbf{2 0 1 4}$ & $\mathbf{2 0 1 5}$ & $\mathbf{2 0 1 6}$ & $\mathbf{2 0 1 7}$ & $\mathbf{2 0 1 8}$ \\
\hline Campus universitário A & 120 & 120 & 120 & 59 & 40 \\
\hline Campus universitário B & 96 & 103 & 83 & 44 & 54 \\
\hline Total & $\mathbf{2 1 6}$ & $\mathbf{2 2 3}$ & $\mathbf{2 0 3}$ & $\mathbf{1 0 3}$ & $\mathbf{9 4}$ \\
\hline
\end{tabular}

Fonte: Silva (2018), com atualizações para este artigo.

Conforme mostrado no Quadro 1, há uma diminuição na quantidade de alunos que ingressaram no curso de Educação do Campo pesquisado nos últimos anos e, segundo nosso entendimento, isso está vinculado a quatro fatores: a) ao corte nas bolsas permanência desses estudantes no ano de 2017 pelo Ministério da Educação - MEC e diminuição drástica da oferta dessas bolsas pela universidade pesquisada em 2018, que ajudam a mantêlos no período de aulas; b) a ausência de um restaurante universitário no campus; c) ausência de transporte que auxilie na locomoção do educando no trajeto da comunidade rural onde mora até a cidade onde está localizada a universidade para fazer o curso; d) a aprovação do Projeto de Emenda Constitucional - PEC n. 55/2016 que paralisa os investimentos públicos em diversos setores, entre eles, o da educação, por 20 anos, o que acaba sendo um retrocesso no desenvolvimento do país.

Com essa PEC, o Plano Nacional de Educação - PNE foi afetado, pois essa política pública destinava um aumento de porcentagem do PIB $^{11}$ do país para a educação em até cinco anos (7\%), chegando a 10\% até 2024, segundo a sua Meta 20 (BRASIL, 2014). Contudo, essas metas provavelmente serão

10 Referente ao ano de 2019.

11 Produto Interno Bruto.

Interfaces da Educ., Paranaíba, v.11, n.32, p. 632 - 661, 2020 
comprometidas, o que afetará negativamente o desenvolvimento da educação brasileira nos próximos anos.

Os participantes desta pesquisa são oriundos dos estados de Tocantins e Maranhão. Moram em assentamentos, povoados, comunidades quilombolas, aldeias indígenas ou na própria cidade, entre outras localidades. Trazem uma larga experiência de vida marcada por uma rica e significativa cultura de sua comunidade, embora marcados por grandes desigualdades sociais, econômicas e politicas. Da turma de 40 alunos matriculados, entrevistamos 36 que assinaram o Termo de Consentimento Livre e Esclarecido - TCLE.

Esses instrumentos de coletas de dados se concretizaram no método do Experimento Didático-Formativo. Davídov $(1988,1978)$ enfatiza que esse método se baseia na estrutura de novos programas de ensino e de procedimentos para efetivá-lo. Tem-se como fundamental a mediação docente, por procedimentos que visam ativar nos alunos outro nível de desenvolvimento, que possibilite avançar/impulsionar a aprendizagem. Parte-se do abstrato para chegar ao concreto, e não o contrário, pois se deve partir daquilo que a pessoa já sabe.

Os estudantes utilizam a palavra como instrumento para se comunicar, e têm no experimento e, consequentemente, na atividade de estudo desenvolvida, o desencadeamento da formação de conceitos. A partir dessa afirmação, é possível considerar que os estudos sobre a formação dos conceitos se concretizam pelo Experimento Didático-Formativo. Desse modo, o experimento seguiu quatro etapas, descritas a seguir.

A) Na primeira etapa realizamos uma pesquisa bibliográfica de autores da teoria Histórico-Cultural, citados ao longo desta investigação, para montar um quadro teórico que pudesse fundamentar o estudo e fizemos um diagnóstico da realidade pesquisada. Levantamos também as necessidades de ensino na disciplina História em Quadrinhos. Além disso, efetuamos uma análise documental ao estudar o Projeto Pedagógico do Curso - PPC e o Plano de Ensino da disciplina de História em Quadrinhos. Vale destacar que 
foi nesse momento que caracterizamos a turma pesquisada (participantes da pesquisa).

B) A etapa seguinte se caracterizou pela elaboração do Plano de Ensino pelos pesquisadores, mas sem alterar os conteúdos da disciplina de História em Quadrinhos já colocados anteriormente. Submetemos esses conteúdos a uma organização didática superior, baseada nas ideias de Davídov e seus colaboradores. Nos pressupostos de Aquino (2015, 2017) e de Davídov (1988, 1978), elencamos os principais critérios científicos para a elaboração do Programa da Disciplina estruturado pelos pesquisadores: a) sem mudar o conteúdo, buscamos os princípios gerais e os fundamentos dos conteúdos; b) elencamos a relação entre os objetivos da disciplina e os conteúdos de histórias em quadrinhos; c) tentamos deixar claro nesse Programa a apropriação da experiência humana com a produção de conhecimento científico por parte dos estudantes jovens e adultos da Educação do Campo; d) propomos tarefas (elaboração dos textos verbais das histórias em quadrinhos e os desenhos dessas histórias, por exemplo) aos alunos, de acordo com as dificuldades deles, que foram solucionados por eles mesmos ao longo das aulas experimentais, com a nossa mediação; e) utilizamos recursos didáticos como o datashow para apresentar imagens de histórias em quadrinhos e a contextualização histórica dessa linguagem aos alunos; f) desenvolvemos o sistema de tarefas de estudo para cada aula experimental (total de 10 aulas de 4 horas cada), divididas em unidades didáticas, que tinham o objetivo de apresentar o sistema conceitual da disciplina trabalhada nesse experimento aos educandos.

C) A observação das aulas experimentais foi o principal instrumento de coleta de dados na terceira etapa desse experimento, pois trabalhamos com registros visuais das histórias em quadrinhos, com a gravação em vídeo de todas as aulas experimentais e com as observações das ações ocorridas na sala de aula ao longo do experimento. Além disso, durante o período de geração de dados, realizamos entrevistas semiestruturadas e individuais com os jovens e adultos camponeses da turma pesquisada e que participaram do 
experimento, com o objetivo de aprofundar as informações obtidas nesse experimento.

D) $\mathrm{Na}$ quarta etapa organizamos e categorizamos os dados gerados para as análises feitas nesta pesquisa. A partir disso, descrevemos e analisamos esses dados, a partir do fenômeno dado e na relação com o problema colocado nesta investigação, o que caracterizou a última etapa do experimento realizado com os jovens e adultos da Educação do Campo.

Nas aulas experimentais, a partir da atividade de estudo, os alunos fomentaram neles mesmos reflexões sobre o aprendizado em curso, incrementando o desenvolvimento. Para Davídov, Slobodchikov e Tsukerman (2014, p. 102), a atividade de estudo proporciona ao aluno superar as próprias limitações nas tarefas, tanto de forma particular quanto nas relações com as outras pessoas, isto é, "para ensinar e mudar a si mesma, a pessoa deve primeiro, saber sobre as limitações e, segundo, ser capaz de transformar os limites de suas habilidades".

\section{Resultados e Discussão}

Embora tenha raizes fortemente marcadas pela filosofia e relacionadas à concepção de belo nas artes, ao longo da história da humanidade a noção de estética passou por inúmeras transformações teóricas, fazendo com que o seu conceito se ampliasse, principalmente na contemporaneidade (JIMENEZ, 1999). Isso foi devido a um fator principal: a arte já não é mais lida e apreciada dentro de cânones como ocorria séculos atrás (VÁSQUEZ, 2005). Ao romper com os padrões estéticos voltados a um ideal de belo, a arte possibilita ao indivíduo retratar a sociedade por diferentes meios, expor a sua subjetividade e conhecimento sem se preocupar com padrões, o que lhe possibilita tomar consciência da própria realidade.

Com o propósito de enriquecer o debate acerca da estética para nos ajudar a caracterizar o termo "letramento estético" nesta pesquisa, destacamos Vásquez (2005) ao esclarecer que qualquer objeto ao qual se atribui alguma qualidade especifica pode fazer parte do universo estético, como, por exemplo, uma paisagem, uma flor entre outros, além daqueles Interfaces da Educ., Paranaíba, v.11, n.32, p. 632 - 661, 2020 
produzidos pelo homem, como uma mesa, o grafite, uma escultura e, inclusive, um texto escrito.

Nesse sentido, entendemos nesta investigação que, embora seja ainda vinculada a "filosofia do belo", a estética pode se debruçar, quando necessário, em outras teorias, como a psicologia, a sociologia, a linguística e principalmente na teoria Histórico-Cultural, pois há autores que permitem fazer esse diálogo, como o próprio Vigotski e Vásquez, por exemplo, que permitem ampliar o conceito de estética na pesquisa em educação.

Nessa direção, Vásquez (2005) ressalta que um dos objetos da estética deve ser a apropriação da realidade e, ao considerá-la, o seu conceito também deve ser ampliado. Isso significa dizer que é possivel estender a sua concepção a outros objetos que, sob determinadas condições e ações, apresentam qualidade estética, como, por exemplo, um texto elaborado por um educando da Educação do Campo, entre outros exemplos. Dito com outras palavras, o autor defende a tese de que a estética deve ter o seu conceito ampliado e compreendido num sentido aberto, para que seus fenômenos não fiquem limitados ou passem despercebidos quando descritos, analisados e explicados.

Foi um dos nossos objetivos nesta investigação: ampliar o conceito de estética a partir da caracterização do letramento estético, realizado nesta pesquisa a partir dos estudos sobre letramento de autores como Kleiman (1995), Stefanello (2017), Rojo (2009) e Mollica (2009). Entendemos que abordar conceitos únicos e tidos como verdadeiros para ambos os termos (estética e letramento) impossibilita que o desenvolvimento da consciência e, consequentemente, a formação de ações mentais nos individuos ocorra de forma plena, pois não compreendemos que a extensa e densa literatura que trate de letramento e estética não impossibilita ampliar seus significados na produção de conhecimento que, por sua vez, está em constante movimento. Com efeito, o concreto da realidade entendido aqui é teórico e não uma mera reprodução do real. Com efeito, a estética não tem uma explicação estética, 
mas abstrata, conceitual, o que dialoga com o aporte teórico da teoria Histórico-Cultural que utilizamos nesta pesquisa.

Para ampliar um pouco mais o nosso entendimento de estética neste estudo, tomamos emprestada a fala de Duarte Júnior (1981) ao dizer que:

É comum ouvir-se, especialmente entre os profissionais da medicina e da psicologia, a seguinte assertiva: 'estou atendendo (ou tratando de) um caso muito bonito'. Ora, será que beleza a que se refere o profissional se encontra em um corpo (ou mente) enfermo? Não. A beleza, aí, reside na relação que ele mantém com um fenômeno que deve ser decifrado. Ela consiste no prazer experimentado por ele ao vencer um desafio imposto pela doença: compreendê-la e atuar sobre ela de forma correta. Sob todo o seu equipamento e raciocínio lógico e científico, subjaz um sentimento da situação que ele interpreta como belo. (DUARTE JÚNIOR, 1981, pp. 31-32).

Como mostra o autor, a qualidade estética é fundamental para compreender a beleza de um objeto, pois o fundamental é entendê-lo em sua essência e enquanto boa forma, bem resolvido. O sensivel aqui demonstrado está diretamente relacionado à experiência de vida do indivíduo com a realidade da qual faz parte. Além disso, as emoções aqui também se fazem presentes, ao "tocar" o individuo na relação estética entre ele e o fenômeno ocorrido, ao conectar a aparência e a essência desse fenômeno.

Nesse caminho desenvolvido, Vigotski (1998) compreende a estética como uma teoria do comportamento estético, que envolve tanto o prazer estético quanto a criação artística. Destaca ainda que esta base sociológica não nega o psiquismo do homem social nem evita de estudá-lo como instrumento mediador nas relações econômicas e sociais que criam diferentes ideologias, mas ressalta a necessidade de estudar o psiquismo, devido ao fato das relações econômicas e a ideologia se distanciarem cada vez mais, e a arte não conseguir ser mais explicada apenas a partir dessas relações econômicas. Nesse sentido, "se está reconhecendo que a arte, no mais aproximado sentido, é determinada e condicionada pelo psiquismo do homem social”. (VIGOTSKI, 1998, p. 11). Dessa forma, compreendemos nesta pesquisa que os conceitos desenvolvidos acerca da estética no 
percurso histórico da humanidade estão diretamente relacionados ao seu desenvolvimento histórico, social e cultural.

Para prosseguirmos com a caracterização do termo "letramento estético", é importante situarmos essa discussão nos estudos de letramento. A esse respeito, Kleiman (1995) entende que dominar os processos de leitura e escrita proporciona aos indivíduos ampliarem o seu conhecimento de mundo, além de se socializarem com diferentes linguagens verbais e visuais a sua volta. Para isso, as experiências de vida e o contato com diferentes meios para se comunicar com a realidade são fundamentais para que o indivíduo se torne mais participativo na sociedade. No que se refere aos jovens e adultos do campo, suas práticas de letramentos envolvem artefatos culturais e saberes construídos ao longo de suas vidas, importantes para dialogarem e compreenderem a realidade da qual fazem parte.

No entanto, considerar as práticas de letramento compreendidas como "práticas discursivas que determinam a produção e a interpretação de textos dentro de determinados contextos". (STEFANELLO, 2017, p. 2723), desenvolvidas no contexto rural pode ajudar a compreender como eles se constituem enquanto sujeitos históricos. Com esse raciocínio, defendemos a escola como uma instituição que deve considerar no processo de ensino e aprendizagem desses educandos essa relação entre o que é construído no campo com aquilo que é ensinado e aprendido na escola, buscando manter uma relação dinâmica entre os saberes do campo com os da cidade. Assim, diferentes práticas de letramento deveriam ser consideradas pela escola nesse processo de desenvolvimento do estudante que vive e trabalha no meio rural, uma vez que essas práticas caminham para o entendimento de letramentos múltiplos ou multiletramentos, pois não se referem apenas à leitura e a escrita, mas também a outras linguagens como as artísticas (ROJO, 2009); neste caso, as imagens ou desenhos de histórias em quadrinhos, importantes para ampliar o conceito de letramento na educação. 
Desse modo, o letramento pode ser definido como "um conjunto muito diversificado de práticas sociais situadas que envolvem sistemas de signos, como a escrita ou outras modalidades de linguagem, para gerar sentidos". (ROJO, 2009, p. 10). Contudo, além de se referir às práticas sociais que envolvem diferentes contextos culturais e diferentes linguagens verbais e visuais (KLEIMAN; SITO, 2016), letramento também diz respeito ao sujeito que, mesmo não escolarizado, está inserido em uma cultura que lhe permite fazer cálculos, decifrar palavras e ler imagens, por exemplo, (MOLLICA, 2009). Ou seja, os estudos sobre letramento devem abordar também as diferentes visualidades e não apenas textos escritos.

Conforme esses autores há diferentes maneiras de se conceituar letramento. No entanto, é possivel identificarmos uma semelhança entre eles: letramento é prática social e cultural que envolve os processos de leitura, escrita e oralidade em contextos urbanos e rurais. Com essa definição, podemos entender letramento estético como uma prática social e cultural que, além de envolver esses processos mencionados, envolve a arte na consolidação dos processos de leitura e escrita do indivíduo. Por isso, é usual, por exemplo, a ideia de letramento matemático, ou seja, a capacidade de ler, escrever e compreender dados da realidade em contexto matemático, conforme Fonseca (2004).

Os processos de leitura e escrita desenvolvidos ao longo do Experimento Didático-Formativo se constituíram de diferentes experiências de vida dos jovens e adultos camponeses, registradas por meio da arte. Essas histórias se desenvolveram nesse experimento no decorrer do Tempo Universidade ${ }^{12}$ e Tempo Comunidade e, na medida em que os conteúdos avançaram, as histórias tomaram forma e se enriqueceram de mais signos

12 Os cursos de Licenciatura em Educação do Campo (LEDOC) no Brasil funcionam por meio da Pedagogia da Alternância, ou seja, ocorrem em períodos de aulas na universidade (Tempo Universidade) e no período denominado de Tempo Comunidade (momento no qual os estudantes retornam para as suas comunidades rurais para pesquisarem, realizarem estágios em escolas, desenvolverem atividades de extensão entre outras tarefas propostas durante o Tempo Universidade pelos professores do curso). Esse sistema educativo é importante, pois respeita a realidade do camponês que trabalha na lavoura e na colheita, por exemplo, que precisa retornar ao campo para trabalhar, mas, sem deixar de estudar.

Interfaces da Educ., Paranaíba, v.11, n.32, p. 632 - 661, 2020 
verbais e não verbais devido ao amadurecimento das funções psicológicas superiores desses educandos no decorrer desse processo. Na sequência, apresentamos a compreensão das práticas sociais no campo e o desenvolvimento da leitura e da escrita desses jovens e adultos camponeses, a partir das histórias em quadrinhos produzidas por eles, reveladas nos desenhos e nos textos verbais, como, por exemplo, da aluna L3,13 que é camponesa do Projeto de Assentamento Água Branca, interior do Estado do Tocantins:

Quadro 2 - Texto da história em quadrinhos da aluna L3.

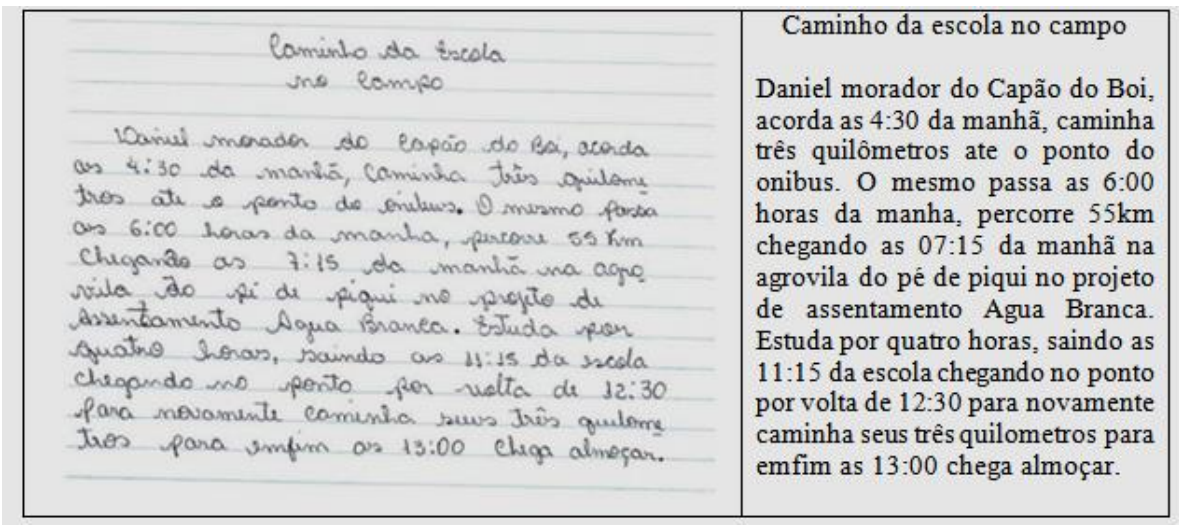

Fonte: Elaborado pela aluna L3.

Ilustração 1 - História em quadrinhos produzida pela aluna L3.

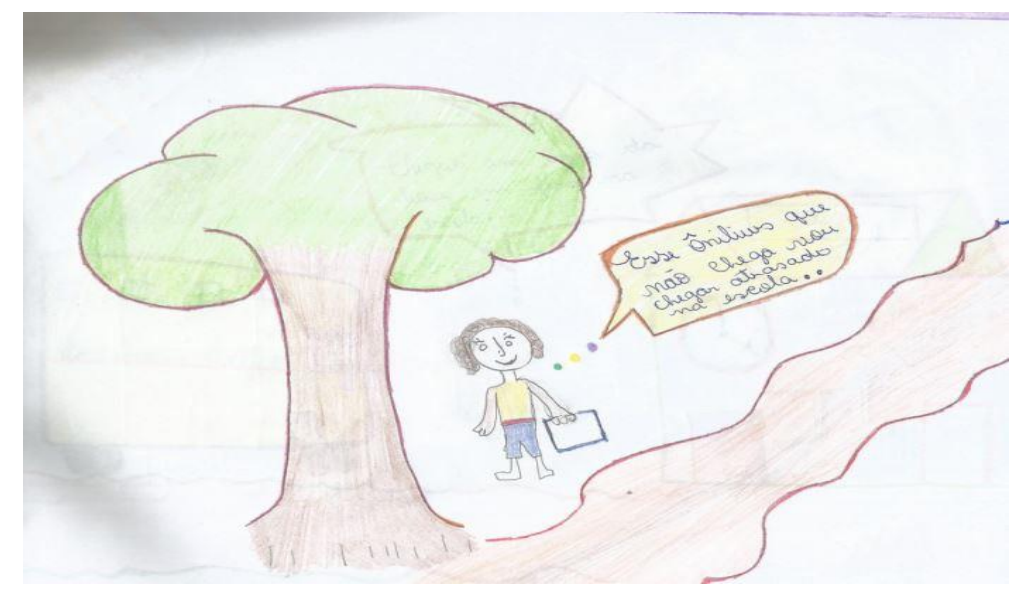

Fonte: Elaborada pela aluna L3.

13 Foram utilizados códigos referentes à primeira letra do nome do sujeito da pesquisa, para identificar os alunos jovens e adultos participantes desta investigação, para preservar o seu anonimato e atender os principios éticos para a pesquisa com seres humanos.

Interfaces da Educ., Paranaíba, v. 11, n.32, p. 632 - 661, 2020 
A história relatada pela aluna L3 desvela a realidade da maioria dos jovens e adultos camponeses que frequentam a universidade: acordar de madrugada, caminhar alguns quilômetros para pegar o ônibus mais próximo (quando tem) para chegarem à instituição (geralmente atrasados). Após o fim das aulas, retornam a suas casas fazendo o mesmo trajeto.

Essa dificuldade para se locomover até a universidade para estudar e que atinge a maioria dos estudantes jovens e adultos do campo participantes desta investigação é um dos motivos de desistência dos estudos. Muitos alunos do curso, além de trabalhadores do campo, ajudam nos afazeres domésticos e cuidam da família. Além disso, ao chegarem à universidade, nem sempre encontram espaço com boa infraestrutura, além de se depararem com a falta de materiais didáticos, como, por exemplo, os materiais referentes às disciplinas de artes no curso, tais como tintas, pinceis, diferentes papeis ou laboratórios de arte.

Pela análise feita, entendemos que os jovens e os adultos do campo não devem ter os seus direitos de estudar com dignidade e qualidade negados pelo Estado, pois deixariam de desenvolver o seu pensamento crítico, histórico e político. É na universidade que o aluno indígena, quilombola, assentado pela Reforma Agrária, quebradeiras de coco, ribeirinhos, atingidos por barragens, entre tantos outros camponeses fazem valer os seus direitos à educação pública, gratuita e com qualidade. Frequentar e permanecer na universidade, além de ser extramente vitorioso para eles, é uma forma de se humanizarem, se reconstituírem enquanto sujeitos históricos e de lutarem por um ensino que é de direito deles também.

Daí, a importância de se investir mais nas Licenciaturas em Educação do Campo - LEDOC - no país, para que se possam formar docentes para atuarem nas escolas do campo e que possam lutar contra as mazelas que a sociedade lhes impõe. As LEDOC qualificam os diversos jovens e adultos camponeses para que atuem nas inúmeras escolas de Educação Básica localizadas no meio rural brasileiro. Destaque-se o fato de que Interfaces da Educ., Paranaíba, v. 11, n.32, p. 632 - 661, 2020 
A educação, no decorrer da história, constitui-se como uma forma de opressão, de exclusão, de fomento das desigualdades. Foi pensada e criada a partir de um referencial de poder de uma classe, sendo destinada às elites, implicando em acesso a poucos. Esta traz em seus principios a hegemonia, a supremacia de um povo sobre outro, de um conhecimento que nega a outros, o que tem gerado lutas contra-hegemônicas das classes. (COSTA; CABRAL, 2016, p. 192193).

De fato, a própria relação entre capital e trabalho ajuda a produzir essas contradições na sociedade, reveladas nas muitas histórias que esses jovens e adultos camponeses relataram nesta pesquisa.

Outra história em quadrinhos analisada desvela um acontecimento significativo ocorrido na universidade pesquisada no ano de 2016: a ocupação dos estudantes dos cursos de graduação desse campus (Pedagogia, Ciências Sociais, Educação Física e Educação do Campo) para reivindicarem a manutenção de direitos sociais consagrados do povo brasileiro, o que, de certa forma, afetava também todos eles, como pode ser visualizado nos quadrinhos abaixo construídos pela aluna A1:

Ilustração 2 - História em quadrinhos produzida pela aluna A1.

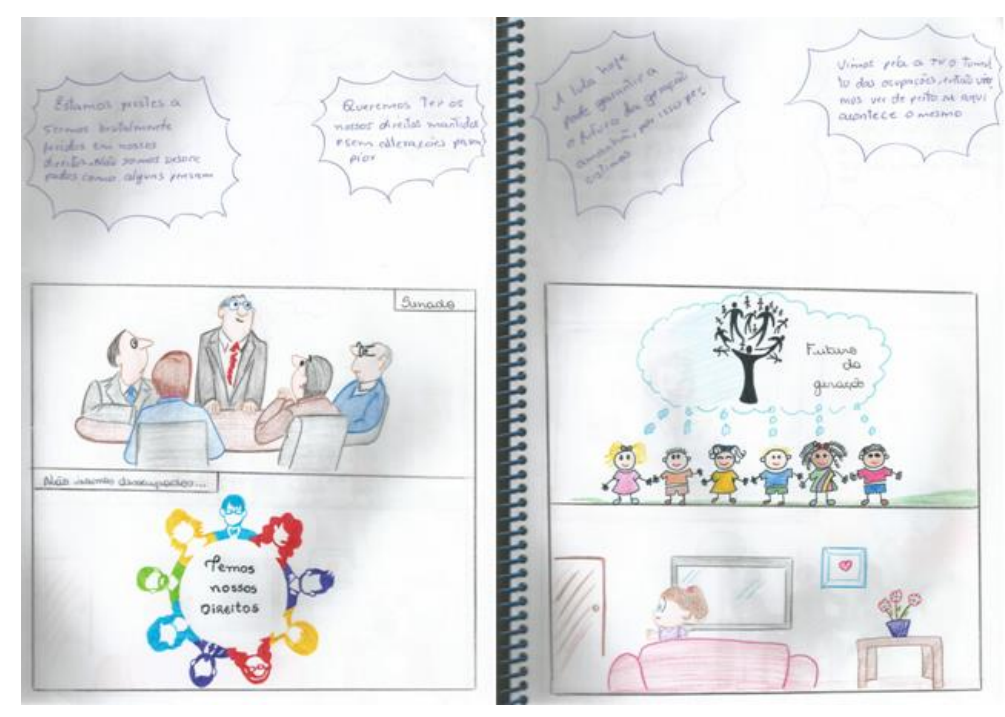

Fonte: Elaborada pela aluna A1. 
Ilustração 3 - História em quadrinhos produzida pela aluna A1.

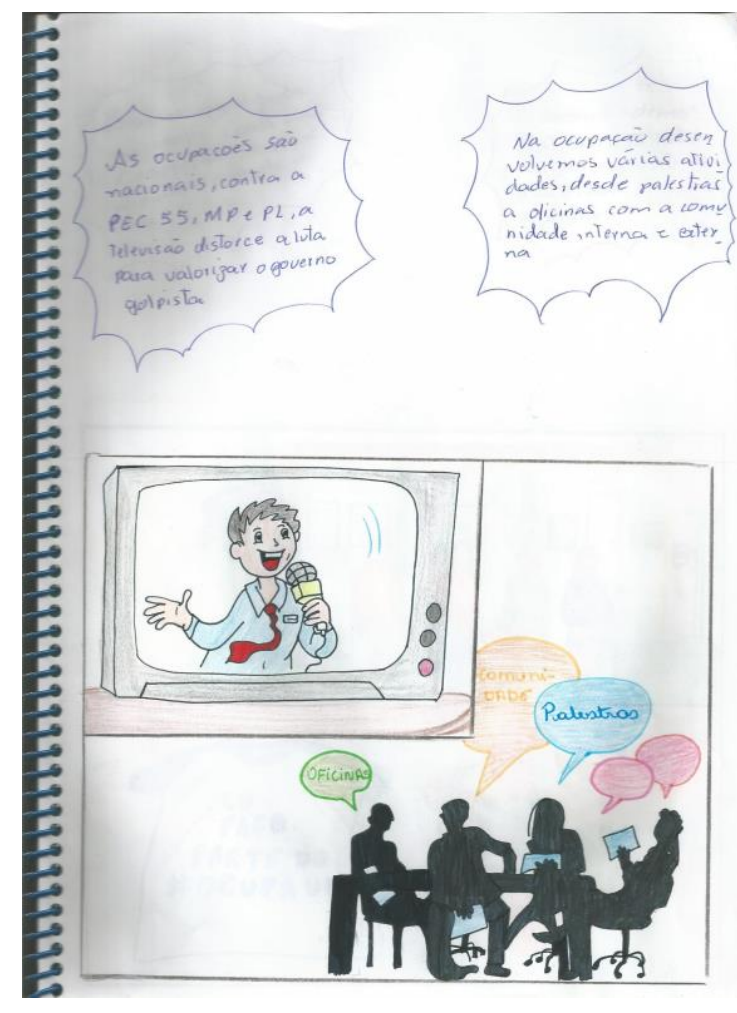

Fonte: Elaborada pela aluna A1.

Diferentes enquadramentos elaborados pela aluna nessa história e a predominância de balões "soltos" nas páginas marcam a sequência visual da história criada por ela, assim como recursos interessantes dessa linguagem como o close up (ilustração 3) utilizado pela aluna com o objetivo de chamar a atenção do leitor para algum detalhe da cena do quadrinho. Isso foi fundamental para materializar por meio de desenhos um evento ocorrido típico da luta de classes: a negação de direitos à população para beneficiar as elites econômicas.

A interpretação de sua história permite afirmar que o resultado das contrarreformas realizadas no país nos últimos anos, como a aprovação da PEC n. 55/2016, denominada de "PEC do Teto dos Gastos", que interrompe por 20 anos qualquer tipo de investimento público em setores fundamentais para o desenvolvimento do país, evidencia o retrocesso no crescimento qualitativo de serviços públicos, como a educação. Assim, com signos visuais 
que ela aprendeu no experimento, a aluna A1 buscou relatar a luta por justiça social.

Para desvelar essas contradições, criou personagens, objetos e cenários como meios para que o leitor abstraia informações que são socializadas pela relação entre palavras e desenhos, fundamental para que possa compreender a história e gerar conhecimento a partir dela. Essa interpretação da realidade é importante, pois por meio da linguagem visual apropriada e utilizada pela aluna, é possivel constatar o desenrolar da narrativa no interior dos quadrinhos e, ao dar sequência de um para o outro, no movimento do pensamento realizado, a visualização da história toma forma e passa a ter sentido para o leitor. Contudo, isso só foi possível por meio da formação do pensamento, uma vez que a HQ produzida pela estudante foi mediatizada pelo coletivo, isto é, pelas relações sociais de produção que estabeleceu com as outras pessoas (colegas da turma, professor e pessoas de seu convivio social), o que lhe possibilitou desenvolver uma atividade consciente que, para Davídov (1988), surge quando o indivíduo cria uma imagem ideal para representar, mentalmente, uma finalidade a ser modificada por ele, assim como a aluna A1 fez por meio da história construída por ela.

Nesse sentido, os sujeitos criam por necessidade para atender a um interesse. Por ser uma necessidade humana, dependem das condições materiais e históricas para que se desenvolvam. Nesse raciocínio, as palavras e as imagens são signos que medeiam a sua relação com o mundo e com o seu consciente. Por isso, criar é formar e transformar. Sem esse processo, a criação e a imaginação se tornam obsoletas e sem sentido para o camponês. É por isso que a criatividade é essencial à vida humana, à vida do trabalhador do campo, pois ela é imprescindivel para a sua existência, enquanto sujeito histórico, uma vez que a criação transforma a natureza e, nessa relação, o homem do campo também se transforma.

Com isso, é possivel afirmar que o estudante camponês vê na universidade um espaço onde poderá exercer o seu direito de estudar, de se 
reconstituir como sujeito histórico, de se apropriar de uma cultura que, às vezes, o nega; de desenvolver a sua consciência crítica, para que possa atuar de forma mais autônoma nas decisões que precisa tomar ao longo de sua vida.

As análises das histórias em quadrinhos nos permitiram compreender também que eles conseguiram expressar pela arte as suas experiências de vida, cultura e as dificuldades que encontram no campo para sobreviverem nele, o que foi importante para que pudessem ressignificar as suas práticas sociais, melhorando os seus processos de leitura e escrita pela apropriação de signos visuais que desconheciam antes de participarem do experimento.

Consideramos, também, que a internalização desse processo foi significativo, revelando que, mesmo ao alegarem em alguns momentos que "não sabiam desenhar", amadureceram as suas formações mentais gradualmente, desenvolvendo a habilidade de desenhar a história verbal que construíram, avançando nos conteúdos e, consequentemente, na aprendizagem, o que foi fundamental para desenvolverem as suas funções psíquicas superiores. Ao ler e analisar os textos escritos e desenhos por eles produzidos ao longo de quase oito meses, constatamos a vida deles se materializando nas letras, palavras e esboços visuais que, embora apresentassem problemas de linguagem, revelaram não apenas signos gráficos, mas sentimentos, sonhos, anseios, medos, perspectivas de uma vida melhor no campo, além de ideias que buscavam concretizar para continuidade na luta pela Reforma Agrária e melhores condições de vida para o seu povo. Ou seja, era a vida deles ali representada pela arte. Com efeito, arte é conhecimento e é cultura; portanto, não é possível dissociá-la das questões agrárias que envolvem os camponeses na interpretação da realidade.

Conforme as histórias analisadas, os jovens e adultos da Educação do Campo lutam para transformar a realidade, marcada por desigualdade social e contradições, pois é na sua transformação que o processo de humanização é retomado, tendo na educação o meio para chegar a isso. Para efetivação 
desse processo, foi preciso buscar novos meios para compreensão e avanço nos conteúdos curriculares, o que só foi possível a partir de uma atividade de estudo que impulsionasse esse desenvolvimento. É nesse sentido que o Experimento Didático-Formativo está relacionado a esse tipo de atividade (atividade de estudo), ao ajudar no desenvolvimento das funções psicológicas superiores dos estudantes via educação, teoria defendida por Vigotski (2010), Davídov (1988) e colaboradores, e a qual socializamos nesta investigação. Consequentemente, o Experimento Didático-Formativo nos possibilitou planejar as atividades de ensino e pesquisa com os estudantes, colocando-as em movimento a partir da produção das histórias em quadrinhos.

\section{Análises das entrevistas realizadas com os jovens e os adultos camponeses}

A educação é uma prática social que não pode se dissociada do processo de construção e relação histórica com os povos do campo, pois ela transforma e tem caráter intencional de contribuir para uma sociedade mais igualitária e democrática. Nesse sentido, não se trata da educação rural, que não considera a realidade camponesa, pois já vem "pronta" e formatada, não focando os saberes e conhecimentos do seu povo. Enquanto a Educação do Campo é um reconhecimento dos valores do camponês, a educação rural reproduz um ensino burocrático e imitativo-repetitivo, o que leva os alunos a reproduzirem uma realidade que não é a deles.

Com o objetivo de compreender os conceitos formados pelos alunos, após terem identificado a relação geral básica durante o experimento, bem como o modo pelo qual eles os relacionavam com as suas experiências de vida e realidade, foram perguntados, entre outras questões, sobre o que entendiam por Educação do Campo. A seguir, alguns relatos e análises.

É uma conquista de direito. Uma educação direcionada a esse público, que não seja adotada de outra realidade. (A2) 
Para mim, Educação do Campo é aquela educação voltada mesmo para aquelas pessoas que estão no campo, e que buscam uma oportunidade de ter um meio melhor de conviver na sociedade... a Educação do Campo é a base para que essas pessoas tenham uma vida digna, e que possam retornar aos seus campos e oferecer essa vida para as pessoas que estão lá. (A4)

Olha, Educação do Campo pra mim é... hoje, ter uma educação voltada para o campo, para os alunos do campo né... que a gente faça os planejamentos, que a gente elabore realmente conteúdos voltados para o campo. (A5)

Trazer o que o aluno do campo tem, da sua área, e o professor trazer o conhecimento dele para o aluno. Juntar os dois para ver se não fica essa aula tradicional... é um mostrar o que o conhecimento do outro tem... porque um professor da cidade para dar aula no campo, ele não vai saber nada do campo, ele vai usar só exemplos da cidade. (C4)

Para mim professor, Educação do Campo, eu acho que a Educação do Campo tinha que ser igualitária né... igual as outras escolas, mas não é. (C5)

Educação do Campo... é voltada para o povo do campo... porque aqui vamos aprender a trabalhar com o povo do campo. (D1)

Nas falas da maioria dos estudantes, a Educação do Campo é compreendida como um projeto de educação voltada à realidade, ao contexto camponês, o que diferencia da educação rural, que não considera as especificidades e necessidades de aprendizagem desses educandos. Revelase que a Educação do Campo é um movimento que, surgido no seio dos movimentos sociais, propõe um novo projeto educacional com metodologias de ensino que, além de atender à realidade de seu povo, enfatiza aspectos importantes como educação popular e a luta pela terra. Ademais, a elaboração de políticas públicas efetivas para atender as suas demandas também são destacadas nesse cenário de desvelamento e busca de conhecimento.

Os jovens e adultos do campo não vão à universidade por obrigação, mas porque eles têm interesse e necessidade de aprender. Eles revelam maior interesse por aquilo que os afetam mais diretamente, como as diretrizes legais de ocupação do campo, os cálculos para medir o terreno para a lavoura, a arte e sua contextualização para aplicá-la nas escolas 
camponesas e ampliarem o conhecimento cultural de seu povo, dentre tantos outros motivos.

Formar homens e mulheres trabalhadores para atuarem como professores nessas escolas é uma forma de contribuir com ações pedagógicas que articulam as necessidades de aprendizagem desses sujeitos contra a visão mercantilista de educação. Ou seja, o território camponês é formado por diferentes indivíduos e culturas que exigem políticas públicas que atendam os seus anseios e demandas educacionais, econômicas e sociais, fundamentais para o desenvolvimento do campesinato frente às investidas do agronegócio, por exemplo.

No entanto, a fala da aluna C5 nos chamou muito a atenção, pois relata que a escola do campo deveria ser igual a todas as outras escolas, mas para ela não é. Essa afirmação revela que, para essa aluna, não há diferença entre Educação do Campo e Educação Rural, pois ela compreende que a escola do campo deve oportunizar acessos aos mesmos conteúdos que a escola da cidade, o que não garante atendimento às especificidades e culturas do campo. A Educação do Campo é para eles mais que uma oportunidade de formação acadêmica, é uma forma de mudarem os seus pensamentos para que tenham novas ideias e possam interferir em suas realidades. A educação voltada às especificidades da população camponesa valoriza o seu povo e conhece a sua essência, tão negada pela sociedade hegemônica.

A atividade de estudo desenvolvida com os educandos teve na formação de conceitos o seu cerne por envolver ao longo do experimento realizado tanto os conceitos espontâneos quando os científicos. Destarte a importância dos primeiros para a aprendizagem, foi necessário promover o pensamento teórico, para que o conceito e, consequentemente a aprendizagem, se desenvolvessem de forma mais efetiva. Para Davídov (1988), entender é pensar conceitualmente, ou seja, enquanto o pensamento teórico se refere à face interior do objeto, expresso por ações mentais, o 
pensamento empírico baseado em suas experiências de vida apenas age em sua exterioridade, o que não é suficiente para revelar a sua essência.

Segundo Davídov (1997), Vigotski compreendia que os conceitos espontâneos (cotidianos) desenvolvem-se em processo que seguem a marcha do concreto ao abstrato, pois o indivíduo não forma o conceito pelo pensamento, mas pela representação geral de uma dada classe de objetos, ao comparar as suas semelhanças e diferenças. Por outro lado, de forma contrária, os conceitos científicos (teóricos) partem da relação desse objeto de forma mediada, e não imediata das coisas, isto é, é preciso abstrair para pensar; portanto, conceituar.

Em outras palavras, o pensamento empírico é formado na comparação dos objetos, o que permite classificá-los, compará-los, analisá-los, resultando no conceito concreto e, consequentemente, na representação geral deles. O pensamento teórico surge exatamente dessa análise, uma vez que é formado mentalmente a partir da transformação do objeto, o que possibilita descobrir a sua verdadeira realidade. Assim, ao chegar a esse pensamento, o camponês consegue, com autonomia, construir mentalmente esse objeto.

Vigotski $(2009,2001,1999)$ salienta que formar conceitos é uma atividade mental superior, pois assim que os jovens e adultos os internalizam, passam a pensá-los de forma mediada. Além disso, os conceitos devem ser entendidos dialeticamente, sendo a perspectiva histórica fundamental para a sua análise. Em suma, a teoria Histórico-Cultural entende que produzir conceitos é construir conhecimentos científicos (PUENTES; LONGAREZI, 2013).

Esse foi um dos motivos para construir o Experimento DidáticoFormativo por meio da atividade de estudo, buscando desvelar a realidade dos educandos, pessoas que carregam uma história de vida pautada por lutas, dificuldades, conquistas e culturas das mais diversas. Com isso, buscamos propor ações que lhes possibilitassem a abstração por meio do movimento de pensamento dialético, para construir os seus conceitos 
mentalmente, questioná-los e descobrir outros meios de trabalhar os conteúdos pela generalização.

Os depoimentos que os educandos nos concederam permitem afirmar que contextualizar os conteúdos para a realidade camponesa abre possibilidade real de impulsionar o interesse e a motivação do sujeito do campo para aprender. Permite fazer da aprendizagem um constante processo de formação e transformação, uma vez que é por meio da linguagem escrita e da leitura que eles se apropriaram de diferentes conhecimentos.

Nesse sentido, as histórias em quadrinhos, a partir de uma atividade de estudo, proporcionaram participação coletiva e interação dos educandos para desenvolvimento de leitura e escrita em sala de aula. As produções avançaram, uma vez que as tarefas trabalhadas no Experimento DidáticoFormativo permitiram o desenvolvimento das suas funções psicológicas superiores pela aprendizagem da linguagem visual (desenhos) e da linguagem verbal (palavras), para muitos deles incipientes até participarem da pesquisa. Com efeito, na perspectiva da teoria Histórico-Cultural, a aprendizagem é fator de desenvolvimento. Nesse sentido, o camponês se depara com um conjunto de fenômenos de seu cotidiano que penetra na sua consciência, mas que não são verdadeiros. Para Kosic (1976), uma vez que são caracterizadas por objetos externos que passam a impressão de serem naturais, as aparências das coisas nada revelam das suas verdadeiras essências, ainda que o fenômeno se manifeste diretamente.

Destaque-se que o processo de produção das histórias em quadrinhos, a leitura dessas revistas e das próprias histórias que eles produziram se relacionavam com a realidade do homem do campo. Com isso, passaram a produzir inferências, hipóteses, comparação e generalização durante as leituras, ressignificando-as enquanto sujeitos históricos que produzem relações sociais e conhecimento. Os processos de leitura e escrita, isto é, os textos verbais e desenhos criados pelos jovens e adultos camponeses socializados neste artigo, não apenas revelam visualmente e verbalmente a vida deles no campo, mas deixam claro que as suas histórias produzidas 
apresentaram temas diversos, que vão desde os relacionados à realidade vivida pelo educando, até aqueles frutos da imaginação.

As histórias relataram diferentes experiências de vida e de conhecimento dos educandos por meio da arte. Além disso, desenvolveram textos verbais e não verbais (desenhos) a partir de suas experiências no meio rural, que colaboraram para desenvolver as suas capacidades psicológicas superiores, fundamentais para o avanço da aprendizagem. Com efeito, as suas produções ao longo do experimento lhes proporcionaram analisar criticamente a realidade da qual fazem parte.

Identificamos que nesses processos analisados os camponeses formularam suas histórias, situando-se como autores. Essas histórias melhoraram o seu vocabulário, pelo fato de terem se apropriado e desenvolvido signos visuais que os ajudaram a construírem as suas histórias e, a partir delas, representar o meio rural brasileiro. Portanto, o desenvolvimento das histórias influenciou os processos de leitura e escrita desses educandos, uma vez que puderam conhecer, ampliar e fazer uso social e cultural da arte no processo de apropriação de signos visuais.

\section{Considerações a guisa de conclusão}

Consideramos que as histórias em quadrinhos podem ser utilizadas por diferentes sujeitos, ampliando o alcance da linguagem dos jovens e adultos do campo e criando outras possibilidades para o desenvolvimento do processo de ensino e aprendizagem. Essa linguagem situa-se numa perspectiva dialética de produção de conhecimento, envolvendo conteúdos que possibilitam ao indivíduo criar e relacionar fatos e ideias, avançando no desenvolvimento intelectual para melhor compreender a sua realidade e nela interferir.

Evidenciou-se também que é possivel descobertas importantes com base em um Experimento Didático-Formativo, complementando estudos sobre o papel do letramento no contexto rural e abrindo possibilidades de novas pesquisas nesta área. As histórias em quadrinhos produzidas mostraram qualidade estética, tanto na escrita quanto nos desenhos Interfaces da Educ., Paranaiba, v.11, n.32, p. 632 - 661, 2020 
construídos por eles, o que demonstra que a beleza de seus trabalhos está inserida no seu desenvolvimento histórico e social, condicionantes da vida e dos processos de leitura e escrita. Ao se depararem com a extensa variedade de signos verbais e visuais das histórias em quadrinhos, os alunos reúnem elementos para ampliar a comunicação, criação e disseminação de ideias e informações necessárias para a construção de conhecimento.

Consequentemente, as histórias em quadrinhos produzidas por eles foram constituídas e reconstruídas histórica e socialmente, pois estão diretamente relacionadas às suas condições de vida no campo. Quando eles abordaram a sua realidade, ao produzirem um trabalho de arte, atribuíram significados e reconheceram sentidos, formando conceitos a partir da linguagem aprendida, o que levarão para as suas vidas, pois são elementos fundamentais para socializar novas formas de conhecimento na perspectiva de ensino desenvolvimental.

As histórias em quadrinhos motivam a leitura e a realização de práticas artísticas pelo educando, proporcionando beneficios para a sua formação e constituem avanços interessantes em sua aprendizagem com os signos visuais, ampliando a sua compreensão de leitura, uma vez que a linguagem, enquanto interação social, não comunica apenas por palavras, mas também por imagens. Embora muitos desses jovens e adultos do campo não tenham tido contato com as histórias em quadrinhos antes de ingressarem na universidade, é correto dizer que em suas vidas essa linguagem torna significativa a interação deles com as pessoas de seu meio, observando e interpretando diferentes signos para se comunicarem com elas, o que é importante para a formação intelectual. Desse modo, o ensino desenvolvimental é uma forma de garantir uma atividade de ensino problematizadora, contextualizada e desenvolvente, possibilitando maior autonomia e autocontrole nas tarefas a realizar, algo que o ensino tradicional não consegue realizar plenamente.

Se os alunos podem escrever melhor após produzirem histórias em quadrinhos, pois como tiveram que ler e reler os textos das histórias por eles 
produzidas inúmeras vezes durante o processo de construção das HQ puderam encontrar erros ortográficos, de concordância e pontuação em suas histórias, fazendo com que eles corrigissem seus textos, sendo importante para conhecerem novas palavras e entender o sentido do texto que escreviam; se tomaram consciência de sua realidade; se há a possibilidade de melhorarem a escrita e a leitura a partir dessa linguagem; se por meio dos signos verbais e visuais conseguem mostrar as contradições e os conflitos existentes no campo, entendemos que isso é belo, pois tem caráter de obra bem feita e coerente, uma vez que, mais do que incrementar o letramento, as HQ representaram significativamente a essência do campo que poucos brasileiros conhecem.

\section{Referências}

AQUINO, O. F. O Experimento Didático-Formativo: contribuições de L. S. Vigotski, L. V. Zankov e V. V. Davídov. In: LONGAREZI, A. M.; PUENTES, R. V. (Orgs.). Fundamentos psicológicos e didáticos do Ensino Desenvolvimental. Uberlândia: EDUFU, 2017, p. 323-350.

AQUINO, O. F. O experimento didático-formativo: contribuições para a pesquisa em didática desenvolvimental. Uberaba: UNIUBE, 2015, p. 1-13.

BRASIL. Lei n. 13.005 de 25 de junho de 2014. Aprova o Plano Nacional de Educação - PNE e dá outras providências, 2014.

COSTA, M. L.; CABRAL, C. L. O. Da Educação Rural à Educação do Campo: uma luta de superação epistemológica/paradigmática. Revista Brasileira de Educação do Campo, Tocantinópolis, v. 1, n. 2, p. 177-203, 2016. Doi: https://doi.org/10.20873/uft.2525-4863.2016v1n2p177

DAVÍDOV, V. V.; SLOBODCHIKOV, V. I.; TSUKERMAN, G. A. O aluno das séries iniciais do ensino desenvolvimental como sujeito da Atividade de Estudo. Ensino em Revista, Uberlândia, v. 21, n. 1, p. 101-110, 2014.

DAVÍDOV, V. V. O problema da generalização e do conceito na teoria de Vygotsky. Palestra proferida durante o Comitê Internacional do ISCRAT (International Society for Cultural Research and Activity Theory). Tradução de José Carlos Libâneo. Studi di Psicologia dell Educazione. v. 1, 2, 3, Armando, Roma, 1997, p. 1-9. 
DAVÍDOV, V. V. Problemas do ensino desenvolvimental: a experiência da pesquisa teórica e experimental na psicologia. Tradução de José Carlos Libâneo e Raquel A. M. da Madeira Freitas, 1988. Disponivel em: http://professor.ucg.br/SiteDocente/admin/arquivosUpload/5146/material LDavydov. Acesso em 16 de janeiro de 2019.

DAVÍDOV, V. V. La enseñanza escolar y el desarrollo psíquico. Moscou: Editorial Progreso, 1978.

DUARTE JÚNIOR, J. F. Fundamentos estéticos da educação. São Paulo: Cortez Editora; Universidade Federal de Uberlândia; Autores Associados, 1981.

FONSECA, M. C. F. R. (Org.). Letramento no Brasil: habilidades matemáticas. São Paulo: Global/Ação Educativa/Instituto Paulo Montenegro, 2004.

KLEIMAN, A.; SITO, L. Multiletramentos, interdições e marginalidades. In: KLEIMAN, A.; ASSIS, J. (Orgs.). Significados e ressignificações do letramento: desdobramentos de uma perspectiva sociocultural sobre a escrita. Campinas, SP: Mercado de Letras, 2016, p. 169-198.

KLEIMAN, A. (Org.). Os significados do letramento: uma nova perspectiva sobre a prática social da escrita. Campinas, SP: Mercado de Letras, 1995.

JIMENEZ, M. O que é estética? Tradução de Fulvia Moretto. São Leopoldo, RS: Editora UNISINOS, 1999.

KOSIC, K. Dialética do concreto. Tradução de Célia Neves e Alderico Toríbio. 7. ed. Rio de Janeiro: Paz e Terra, 1976.

MOLLICA, M. C. (Org.). Letramento em EJA. São Paulo: Parábola Editorial, 2009.

PUENTES, R. V.; LONGAREZI, A. M. Escola e didática desenvolvimental: seu campo conceitual na tradição da teoria histórico-cultural. Educação em Revista, Belo Horizonte, v. 29, n. 1, p. 247-271, 2013. Doi: http://dx.doi.org/10.1590/S0102-46982013005000004

ROJO, R. Letramentos múltiplos, escola e inclusão social. São Paulo: Parábola Editorial, 2009.

SILVA, C. Políticas públicas para a Educação do Campo e formação de professores. In: ARAÚJO, G. C., MIRANDA, C. F. RUAS JUNIOR, J. P.; SILVA, M. P. (Orgs.). Educação do Campo, Artes e Formação Docente: práticas pedagógicas em Educação do Campo (volume 2). Palmas: EDUFT, 2018, p. 51-73. 
STEFANELlO, P. G. A representação da verdade pelo discurso científico: vistas a uma ruptura de paradigmas do letramento acadêmico. Fórum Linguístico, Florianópolis, n. 14, v. 4, p. 2720-2729, 2017. Doi: https://doi.org/10.5007/1984-8412.2017v14n4p2720

UNESCO Brasília Office. Educação de Adultos: Declaração de Hamburgo Agenda para o Futuro. CONFINTEA V. Brasília: Representação da UNESCO no Brasil, 1998.

VÁZQUEZ, A. S. De La estética de La recepción a una estética de La participación. Ciudad de México: Facultad de Filosofia y Letras/UNAM, 2005.

VIGOTSKI, L. S. Psicologia pedagógica. São Paulo: Martins Fontes, 2010.

VIGOTSKI, L. S. Imaginação e criação na infância: ensaio psicológico. Tradução de Zoia Prestes. São Paulo: Ática, 2009.

VIGOTSKI, L. S. A formação social da mente: o desenvolvimento dos processos psicológicos superiores. São Paulo: Martins Fontes, 2007.

VIGOTSKI, L. Pensamento e linguagem. São Paulo: Ridendo Castigat Mores, 2001.

VIGOTSKI, L. S. Obras Escogidas III. Madrid: Aprendizage Visor, 2000.

VIGOTSKI, L. S. Teoria e método em psicologia. Tradução de Claudia Berliner. São Paulo: Martins Fontes, 1999.

VIGOTSKI, L. S. Psicologia da arte. São Paulo: Martins Fontes, 1998. 